\title{
CONSUMER BUYING BEHAVIOUR OF VIRGIN EDIBLE OILS - A LITERATURE SURVEY AND CONCEPTUAL FRAMEWORK
}

\author{
Ganesh RS \\ Research Scholar, RVS Institute of Management Studies \& Research, \\ Coimbatore, Tamilnadu, India \\ Dr. Sunil Vakayil \\ Director, RVS Institute of Management Studies \& Research, \\ Coimbatore, Tamilnadu, India
}

\begin{abstract}
With the growing importance of inter disciplinary approaches in management, it was also relevant to study the impact of consumer behaviour towards buying virgin edible oils. In the present study, the author tried to understand the combination of factors influencing the buying behaviour of virgin edible oils. Further the literature review approach as carried out to understand the definite gap that exists in the selected area of research. Also the study added two more variables to the study say, consumer awareness, attitude and the level of satisfaction towards the future buying potential of the edible oils. This would enhance the focus of consumers on buying decision of the edible oils which in turn would help to understand the customer pulse based on the identified relationship between the variables of the study. Vast literature was assessed on all the variables and the research gap was identified paving way for an important objective of studying the impact of factors influencing customer buying behaviour of virgin edible oils.
\end{abstract}

Key word: Consumer Buying Behaviour, Level of Satisfaction, Virgin edible oils, Literature survey, Conceptual Framework

Cite this Article: Ganesh RS and Dr. Sunil Vakayil, Consumer Buying Behaviour of Virgin Edible Oils - A Literature Survey and Conceptual Framework, International Journal of Management, 10 (4), 2019, pp. 141-151. $\mathrm{http} / / /$ iaeme.com/Home/issue/IJM?Volume $=10 \&$ Issue $=4$

\section{INTRODUCTION}

Edible oils constitute an important component of food expenditure in Indian households. Historically, India has been a major importer of edible oils with almost $30-40 \%$ of its requirements being imported till 1980s. In 1986, the Government of India established the Technology Mission on Oilseeds and Pulses (TMOP) in order to enhance the production of oilseeds in the country. The TMOP launched special initiatives on several critical fronts such 
as improvement of oilseed production and processing technology, additional support to oilseed farmers and processors besides enhanced customs duty on the import of edible oils. Consequently, there was a significant increase in oilseeds area, production, and yields until the late-1990s. Awareness, knowledge \& exposure among consumer towards edible oil are also increasing, because of the level of education, urbanization and also the vast development in communication facilities. Packaging has become appropriate selling proposition now days, although edible oil industry is very competitive and consumers are numerously price conscious but still packaging make an impact on the consumer buying behaviour.

As a first step in the research process, attempt was done to find out the research gap. In connection to this, the literature survey was carried out on two basic fields say, consumer buying behaviour and edible oil industry. From the literature survey, the present study found its gap and the constructs as given below.

\section{REVIEW OF LITERATURE}

Dr.J.H.Vyas, Imran N.Siddiqu ,Jay K.Dewangan (2019) study suggests that when the consumer purchase cooking oil higher importance is given to safety aspects, and the brand image of the cooking oil than the sales promotional schemes offered by the companies. Cooking oil marketers could take maximum efforts in designing the advertisements in such a way that the advertisements provide reliable and maximum information about the nutrition and health aspects, price of the oil.

Dhinesh babu \& Venkateshwaran (2018) stated that the owners of the edible oil units should be trained to get more marketing knowledge to market their products. They should think global and act local. It implies that their product should be highly qualitative and also suitable to the local consumers. The attractive packaging plays an important role in the marketing of edible oils. All types of manufacturers should realize this fact and try to sell their products in attractive packets. It is not only attractive but also is reachable to all customers' segments.

R Prenna (2018) in their study says that Quality is always important for any production. But it is more important in case of edible oil for reason that it is more related to health. Consumers analyze the price, quality, packaging aspects etc. before they buy the product and hence, it is up to the different brands of sunflower and groundnut oil manufacturers to concentrate on those aspects and workout better strategy to attract more consumers for their brands.

Syed Akif Hasan and Muhammad Zeeshan Khan (2017) stated that packaging characteristics influences the consumer brand preference in edible oil. whereas packaging characteristics has eight different dimensions i.e. various sizes of Package, different shapes Package, safety, shelf life, convenience of storage, convenience of use, extra use of package and package attractiveness. Study is also helpful to conclude the factors which are responsible for the increment of market share in edible oil industry by changing or modifying the packaging of product in competitive market.

Butz and Goodstein, (2018) found that demographic variables are the most popular bases for segments the customer groups, One reason is that consumer needs, wants, preferences and usage rates are often highly associated with demographic variables.

N. Rajaveni \& Dr. M. Ramasamy (2018) study suggests that strongly packaged brand should offer protection and carve out for a point of difference that can protect the brand against competitor activity through trade marking. It is also important to remember that the world is full of cultural and linguistic difference. What works in one market doesn't always work in another. The bottom line for business is that packaging design will almost always have an effect on a company's profit and loss. 
SoonyongBae, Taesik Lee (2010) they investigates the effect of consumer reviews on consumer's purchase intention. In particular, they examine whether there are gender differences in responding to online consumer reviews. The results show that the effect of consumer reviews on purchase intention is stronger for females than males. The negativity effect, that consumers are influenced by a negative review more than by a positive review, is also found to be more evident for females. These findings have practical implications for sellers to guide them to effectively use online consumer reviews to engage females in online shopping.

Isaac J. Gabriel (2007) studied consumers' risk perceptions and will reveal a "cognitive map" of their attitudes and perceptions to risks. It was accomplished by composing a master list of online hazards and activities, measuring current level of perceived risk, desired level of risk, and desired level of regulation associated with them, composing a master list of risk characteristics, determining risk dimensions, and revealing position of each hazard or activity in the factor space diagram. A factor space diagram captures a graphical representation of the results of the factor analysis. This study is still in progress and results are not available yet.

Guda Van Noort, M.A., Peter Kerkhof, Ph.D and Bob M. Fennis, Ph.D. (2007) in two experiments, the impact of shopping context on consumers' risk perceptions and regulatory focus was examined. They predicted that individuals perceive an shopping environment's more risky and that an shopping environment, by its risky nature, primes a prevention focus. The findings in Study 1 demonstrate these effects by using self-report measures for risk perception and prevention focus. In Study 2, replicated these findings and demonstrated that the effect of an online shopping environment carries over to behaviour in a domain unrelated to shopping.

Seyed Rajab Nikhashem, Farzana Yasmin, AhsanulHaque. (2011) Studied that investigated peoplese ${ }^{\text {ee }}$ perception as well as why some people use this facility while some who do not use it stick to the traditional way to fulfill their needs. In addition, factors such as what inform peoplese eagerness and unwillingness to use internet facilities are also examined. The outcome of this research showed a comprehensively integrated framework that can be utilized by policy makers and business enterprises to understand the dynamic relationships among dimensions of perceived risk, user trustworthiness, usefulness, familiarity and confidence. Also, this study considered how price perception and security can be utilized to understand the consumers ${ }^{\text {ee }}$ perception.

Yu-Je Lee, Ching-Lin Huang, Ching-Yaw Chen (2011) The purpose of this study is to use structural equation modeling (SEM) to explore the influence of consumers' perception on their purchase intention. Through literature review, four constructs were used to establish a causal relationship between perception of consumers' purchase intention. Results of this study show that product perception, shopping experience, and service quality have positive and significant influence on consumers' purchase intention, but perceived risk has negative influence on consumers' purchase intention, and shopping experience is most important

RaminAzadavar, Darushshahbazi, and Mohammad EghbaliTeimouri. (2011) examined the factors influencing consumers' perception of shopping and developed a causal model that explains how this perception affects their shopping behavior. Research found that factors like, trust, customer service, customers' income, price of products or services and security are more important to encourage people to purchase online the computer related products and services. In other side factors like product customization and price of product were not much effective on purchasing behavior of the respondents. So high level of security in marketing of computer related products and services has this potential to growth more and more to encourage people to reduce the time and cost of transaction. Most important concern regarding to online shopping is the security of transactions. The study intends to explore the understanding of consumer behavior regarding to the direct and indirect influences of the perceptions of online shopping on consumer behavior. Based on our analysis first, a factor 
analysis was conducted on the student's perception of 13 items, and three factors, "convenience, anxiety regarding security, and "poor navigation", were extracted. A model was created reflecting the direct influence of these three "perception"-related factors on behavior or their indirect influence through consumers' attitudes.

Kanwal Gurleen. (2012) focuses on the understanding of demographic profiles of adopters and non-adopters of shopping. For this purpose the data from 400 respondents was collected in the form of questionnaires. The study has been conducted in 3 cities of Punjab, a sample of urban respondents were selected from the Jalandhar, Ludhiana and Amritsar The paper also analyses the various reasons for adoption and non-adoption of online shopping.

Zaryab Ali et al. (2013) study identifies major factors affecting consumption of edible oil in Pakistan. Data was collected from primary. Many factors affecting consumption of the food in Pakistan and it is a key ingredient of household population growth, urbanization, brands liking and disliking. In demand function of oil income, share expenditures oil and family size was significantly affecting the consumption of edible oil. The effect of price was negative but insignificant. In demand function of ghee income, family size, share expenditure of ghee, were insignificant for the consumption of ghee. From the research analyzed that majority of the population used ghee in the cooking in Pakistan. Prices of edible oil should be lowered so that poor people can also use it in their meals as it is better from health point of view.

H. R. Kulkarni et al. (2017) through this study, author has highlighted the brand references for edible oil by consumers. Efforts have been made to understand the various factors which are taking into consideration while purchasing edible oil. Through the study author has also highlighted the variants of edible oil preferred by the consumers. This study is also focused on the awareness of consumers regarding the weight, expiry date, ingredients etc. of edible oil. It is found that, in a city like Pune, majority of families monthly income is between incomes is between Rs. 20,002 Rs. 30,000, 34\% families monthly income is above Rs. 30,000. Therefore all these families preferred branded edible oils. The family is whose monthly income is below Rs. 10,000 preferred cheap/unbranded/loose edible oil. Easy availability and price of edible oil, are the most significant factors which are most influencing on the decision-making for purchasing particular brand of edible oil in a apart from this, health issue taste of labour also important factors in decision-making. Sample house hold have a push down less interest in understanding the factors like ingredients, net weight, nutritional benefits, expiry date etc.

Horsu Emmanuel Nondzor et al. (2015) study was to ascertain consumer's knowledge, perceptions and preference of edible oil. A cross sectional approach was used for study. Pretested semi-structured questionnaires were administrated to 206 respondents. As the consumers are becoming more enlightened in their food intake, their quest for the right combination of food nutrients has become more eminent especially as several health-related problems are attributed to food that they consume. Refined edible oils were preferred by consumers, and were normally purchased from supermarkets for almost all their meals. Unrefined edible oils however were used mostly when needed and normally purchased in open markets. It was clear from the study that the totality of consumer's decision of buying both refined and unrefined edible oils are influenced by their perceived knowledge on edible cooking oils.

Mitul Deliya et al. (2012) have studied the "Role of Packaging on Consumer Buying Behaviour- Patan District". The research was conducted through the Exploratory Research as well as Descriptive Research. The Sample size of 150 Customers was surveyed. A structured questionnaire with rating scale was used to collect primary data. Z- Test was used as a test to verify the different objectives. They found $67 \%$ Consumers are influenced by Packaging and $33 \%$ are not influenced. Brand name is highly rated with $74 \%$ and convenience is rated lowest with $68 \%$ in packaging of FMCG products. Only $26 \%$ of consumers are influenced by packaging while switching from one brand to another brand. 
Lisa M. Soederberg Miller et al. (2015) reviewed whether consumer nutrition knowledge is important for communication of nutrition information through labels on packaged goods. A cognitive processing model posits that consumers with prior knowledge are more likely to use label information effectively, that is, focus on salient information, understand information, and make healthful decisions based on this information. They reviewed the literature on food label use related to three types of food label information: nutrition labels, ingredient lists, and claims. Typically, food label use studies focus on nutrition labels; however, ingredient lists and health/nutrient claims also play important roles in conveying the productes diet and health information to consumers and, for this reason, are regulated in the US by the Food and Drug Administration (FDA). They identified 32 papers that examined nutrition label use and nutrition knowledge. The majority of these studies $(n=28)$ reported significant associations between nutrition knowledge and nutrition label use. In 18 studies, knowledgeable consumers were more likely to comprehend nutrition labels better than those with lower levels of knowledge. Their research yielded only one, relatively small study, reporting no associations between nutrition knowledge and comprehension of nutrition labels (Block \& Peracchio, 2006) in ingredients lists three studies investigated of this area of the food label.

In notable exception, Walters and Long (2012) examined the effects of expertise on types of information used to evaluate product quality and purchase intention. Experts, defined as completion of an upper division nutrition course, were more likely to use ingredient list information rather than an "all natural" label claim. Novices, on the other hand, did the opposite. There are only a handful of studies investigating the influence of knowledge on the comprehension of claims on food labels. In general, these studies show that nutrition knowledge supports understanding of claims on food labels. Howlett et al. (2008) investigated the effects of trans-fat knowledge through the exposure to educational materials prior to the rating task. Participants rated the healthfulness of a food package that fell into one of four conditions: presence of "low trans-fat" claim crossed with high $(4 \mathrm{~g})$ or low $(1 \mathrm{~g})$ trans-fat levels in the nutrition label. Study 1 showed that high-knowledge individuals were sensitive to trans-fat levels on nutrition labels, whereas low-knowledge individuals made similar ratings regardless of trans-fat levels. However, this pattern was not observed for the trans-fat claim manipulation. Study 2 showed large effects of manipulated knowledge for those who use labels frequently, but less so for those who do not. In general, this study provides support for the notion that nutrition knowledge supports nutrition label as well as claim understanding. Consistent with the notion that knowledge-is-power, the findings of this review suggests that nutrition knowledge supports food label use. Although the literature surrounding the use of ingredient lists is limited, evidence from studies investigating nutrition from prior knowledge. Although the review highlights gap in the literature, especially surrounding the role of knowledge among

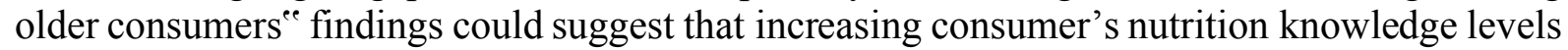
may improve nutrition communication through food labels.

Norhidayah Azman et al. (2015) aimed to summarize and draw the common definition of nutritional label found in the use of previous studies. Besides that, paper also discusses the types of label formats that could influence the use of nutritional label amongst consumers. In addition, the paper also rationalizes the roles of nutritional label in consumer decision in buying healthy foods and highlights the relevant issues for future research undertakings.

Ayodhya Uttamrao Dudhate (2017) studied about the type of information used by consumers while buying the food products and to assess the awareness of the consumers regarding nutrient information given on food label. The researcher also studied the consumer's awareness about health claims disclosed on food label. Random sampling method was utilized while selecting the sample. A total of 200 consumers from four different professions such as doctors, lawyers, professors (university/college) and businessmen 50 in each group were 
selected by purposive random sample technique from Parbhani city. They were between 30 and 60 years of age. T-test was applied to determine the awareness regarding food label by the selected consumers of different professions (Panse and Sukhatme, 1985). In nutshell it can be said that there is a need to educated consumers in regard to information of nutrient content and health claims written on food label. Consumers should be made aware of relation between healthy diet and its implication on health and disease. The nutritional label should be made more consumers friendly. So that it will be helpful for the consumers in making rational food choices.

Sidiga Washi (2011) to assess the consumer's knowledge about the importance of reading the food labels to assist them to take right decisions when buying pre-packaged foods. Researcher reflected on some of the consumer's view on foods labels, and what they want to see on them. The study was conducted in Al-Ain major Food Market Centres during SeptemberDecember, 2009. A sample of 1200 Adult subjects (represent 3.2\% of Al Ain total population) was conveniently selected from shoppers at five major geographic sections. A validated questionnaire was used to collect demographic, and food label behaviour data, in addition to information on what consumers were like to see on the food label. The overall knowledge of the consumers did not show significant correlation with the overall level of education of the consumers in this study. A lot of work is needed to raise the level of awareness of the consumers about the nutrition aspects of the food labelling in order to assist them to make their best healthy food choices. The study recommended further studies on the impact of different forms of labelling on the consumer's ability to make use of the information on them.

Nadia van der colff et al. (2015) aimed to describe consumers ${ }^{\text {ee }}$ retrospective satisfaction with food labels within the expectancy (dis)confirmation paradigm and to investigate the likelihood of food labels influencing consumerse product choices. A quantitative, descriptive, cross-sectional survey approach was followed to explore and describe consumer's satisfaction with attributes of and information on food labels. Self-administrated questionnaires $(n=279)$ were distributed in Gauteng, South Africa, through convenience sampling. Data were analyzed using IBM SPSS Statistics Version 17.

Descriptive statistics and factor analysis were conducted to distinguish label information of primary and secondary importance to consumers. Inferential statistics, such as dependent Ttests, were used to perform a gap analysis by comparing expectations and the performance of various food label elements to deduce respondent's satisfaction. ANOVA was used to determine significant differences between demographic characteristics and respondent's expectations and performance judgement of food labels. Turkey post hoc tests and T-test were used to identify significant differences between specific demographic subcategories. P-Values were determined to indicate statistical significance, but due to nonprobability sample, Cohen ${ }^{\text {ee }}$ $\mathrm{d}$-values as effect sizes were reported to indicate practical significance. Responses in the openended question were categorized and coded, whereupon frequency distributions were performed. The results indicate that consumers are only partially satisfied with food labels, as they are dissatisfied with both label attributes and primary label information. Primary food label information (expiry date, allergens, nutrition/health, ingredient list, quality guarantees) tended to be more important to respondents than secondary information (usage instructions, manufacturer name, symbols, serving numbers, country of origin) and more likely to influence their product choice. Therefore, to optimize food label satisfaction and the decision-making process, it is recommended that product managers and label designers should focus more on primary label information and how it is portrayed. This study was the first of its kind and contributed to the expectancy (dis)conformation paradigm during the pre-purchase evaluation phase of decision making in food content. It might also encourage researchers and role players in the industry to further investigate consumers ${ }^{\text {ee }}$ satisfaction with food labels. 
Jabir Ali et al. (2009) aimed at identifying the factors influencing consumers ${ }^{\text {ee }}$ perception on food labelling and its impact on food purchase decision making, through personal interview of respondents using a structured questionnaire. The collected data was entered in SPSS spread sheet and simple statistical analysis were carried out such as descriptive statistical analysis, cross-tabulation, frequency distribution and chi-square statistics to assess the consumer's perceptions on food labelling. To identify the important aspects of food labelling, factor analysis was conducted to identify the underlying dimensions among a set of food labelling attributes. The Kaiser criterion was used to retain only those factors with eigen values greater than 1. A logistic regression model was estimated to predict the likelihood or probability of food label usage at the time of food purchase by consumers. Food labels play an important role in influencing the buying decision by building consumers ${ }^{\text {ee }}$ confidence in the safety and quality of the food, and by increasing consumer awareness on diet and health. Analysis of mean scores of urban consumers indicates that every food label should contain information on product price, manufacturing date along with the best before and expiry dates, name and address of the product manufacturer and information on nutritional contents for better management of health risk. The analysis clearly indicates that educated male consumers of young age, belonging to higher income groups and living in comparatively larger cities require more technical information on a food label as compared with others.

Daleen Van der Merwe et al. (2009) study focused on the importance of label information food in student consumer's decision-making process when exposed to limited label information food in a cafeteria environment. Because of a paucity of research in this area, a qualitative research approach that was exploratory in nature was used, accompanied by semi-structured interviewing and a vignette. The study has indicated that both internal related and productrelated strategies are applied when food choices are based on limited label information. Participants with an interest in food labels were more inclined to use strategies that included label information when making a food choice. Where participants showed a disinterest in label information and no label related strategies were used, they relied on product and personal information on which to base their food choice. When student consumers had to make a food choice regarding limited label information, the pre-purchase search stage of their decisionmaking process relied on label information such as nutrition information, preservatives, energy content, low GI status and allergens. Through more easily understandable, accessible and complete label information, student consumers with a label interest might potentially make easier and healthier food choices. The study points to the fact that food manufacturers need to provide food products with labels that not only comply with the minimum amount of label information required by law, but also meet the expectation of student consumers with a label interest by providing specific and correct information on cafeteria food products.

Mary Alton Mackey et al. (2009) study examines the ease of finding and reading for mandatory label components on selected Canadian food products. A validated typographical scoring system assessed the list of ingredients on a purposive sample of 100 food labels representing foods in all groups in Canada's Food Guide. Seven per cent of the ingredient lists were easy to read; $26 \%$ were difficult to read and $67 \%$ were very difficult to read. Well-educated resourceful readers in consumer focus groups examined food labels for key elements that influence ease of finding and reading information. Focus groups and typographical scoring identified: color contrast, case, print style, print size, space between the lines, reverse print, organization, justification, and type of surface, hyphenation and print reproduction as factors that affect ease of reading. Words placed over illustrations, busy backgrounds or watermarks increase reading difficulty. Hazard statements, instructions, and storage information imbedded in other information without added space or appropriate heading is difficult to find and read. Canadian consumers echo consumers in 28 European countries who find label information difficult to find and to read and want clear guidelines/regulations on the placements and the 
typography of mandatory food label components. Finding and reading information is more difficulty when there is no paragraphing organization of the text to provide clues for the reader to the location and importance of information. When the information sought is in the middle or at the end of a list of ingredients, imbedded in other information or on a different plane, more than one reading may be needed to find it. Key elements that influenced the ease of finding and of reading of mandatory components of food labels in this study were: color contrast, case, print style, print size, space between the lines, reverse print, organization, justification and type of surface. Mandatory labeling components should be in a predicable location on the label. In Canada, consumers have requested clear guidelines be developed to ensure that all mandated components on food labels are easy to read and easy to find for all consumers.

Sejal Jain et al. (2019) conducted a cross-sectional study conducted among 1832 consumers in two metro political cities of India, New Delhi and Hyderabad reported that 12\% of the participants bought pre-packaged food almost daily and almost $92 \%$ of the participants reported of referring the food labels for checking quality and genuineness. Only one-fifth of the participants reported that they will check food labels for nutritive values. Around $58 \%$ of the participants felt that nutritive information given on the food label was inadequate. The sample size of 153 was calculated with $90 \%$ proportion of study participants read the labels in the study conducted in India, 5\% absolute precision, and 10\% nonresponse rate.

The information on consumere s socio demographic characteristics, purchasing behavior, and use and understanding of the food labels were collected using a pretested semi-structured questionnaire. The questionnaire was originally prepared in English based on previous literature and linguistically validated in Tamil language by translation-back translation by two separate bi-linguistic persons. From each supermarket, 51 consumers were selected through convenient sampling, and informed consent was obtained from them. The data were entered in Microsoft Excel and analysed using Epi Data Analysis software. The association between consumer characteristics and awareness regarding food label was analysed using Chi-square test. $\mathrm{P}<0.05$ was considered for statistical significance. The study reported high level of awareness of food labels and preference of the food items with the food labels. However, the ease of understanding of the food label was reported very less. Multispectral involvement, such as public health, social welfare, food and agriculture department in education the public as well as regulating the food manufacturers.

Swetha Kodali et al. (2018) paper reviews the literature on food labelling and its influence on consumer buying to inform current investigations and identify areas of future research. A structured search was undertaken of research studies on consumer use, understanding of, preference for, perception of information on label and purchasing behaviours relating to food labels. From in depth literature survey, it can be concluded that research was focused on understanding the influence of labels on consumer behaviour, but influence of different label features such as font size, placement of label, clarity of language, visibility of essential information and font colour were not explored. Food labels were read by the consumers for brand comparison and but not for consulting nutritional information. The study aspects of food labelling to enable them to make more informed purchasing decisions and better understood consumer purchase intentions and the usefulness of food product labels.

Zaryab Ali et al. (2013) study identifies major factors affecting consumption of edible oil in Pakistan. Data was collected from primary. Many factors affecting consumption of the food in Pakistan and it is a key ingredient of household population growth, urbanization, brands liking and disliking. In demand function of oil income, share expenditures oil and family size was significantly affecting the consumption of edible oil. The effect of price was negative but insignificant. In demand function of ghee income, family size, share expenditure of ghee, were insignificant for the consumption of ghee. From the research analyzed that majority of the 
population used ghee in the cooking in Pakistan. Prices of edible oil should be lowered so that poor people can also use it in their meals as it is better from health point of view.

H. R. Kulkarni et al. (2017) through this study, author has highlighted the brand references for edible oil by consumers. Efforts have been made to understand the various factors which are taking into consideration while purchasing edible oil. Through the study author has also highlighted the variants of edible oil preferred by the consumers. This study is also focused on the awareness of consumers regarding the weight, expiry date, ingredients etc. of edible oil. It is found that, in a city like Pune, majority of family's monthly income is between incomes is between Rs. 20,002 Rs. 30,000, 34\% family's monthly income is above Rs. 30,000. Therefore, all these families preferred branded edible oils. The family is whose monthly income is below Rs. 10,000 preferred cheap/unbranded/loose edible oil. Easy availability and price of edible oil, are the most significant factors which are most influencing on the decision-making for purchasing particular brand of edible oil in a apart from this, health issue taste of labour also important factors in decision-making. Sample house hold have a push down less interest in understanding the factors like ingredients, net weight, nutritional benefits, expiry date etc.,

Horsu Emmanuel Nondzor et al. (2015) study was to ascertain consumer's knowledge, perceptions and preference of edible oil. A cross sectional approach was used for study. Pretested semi-structured questionnaires were administrated to 206 respondents. As the consumers are becoming more enlightened in their food intake, their quest for the right combination of food nutrients has become more eminent especially as several health related problems are attributed to food that they consume. Refined edible oils were preferred by consumers, and were normally purchased from supermarkets for almost all their meals. Unrefined edible oils however were used mostly when needed and normally purchased in open markets. It was clear from the study that the totality of consumer's decision of buying both refined and unrefined edible oils are influenced by their perceived knowledge on edible cooking oils.

Research Gap: All the above studies and many other studies have highlighted the consumer buying behavior and the state of edible oil industry. However, so far no attempt has been made to study the factor use influence on virgin edible oil consumer behavior in Coimbatore District of Tamil Nadu. The present study fills this gap. Keeping this an objective, the present study focuses on the following framework for its research.

\section{CONCEPTUAL FRAMEWORK}

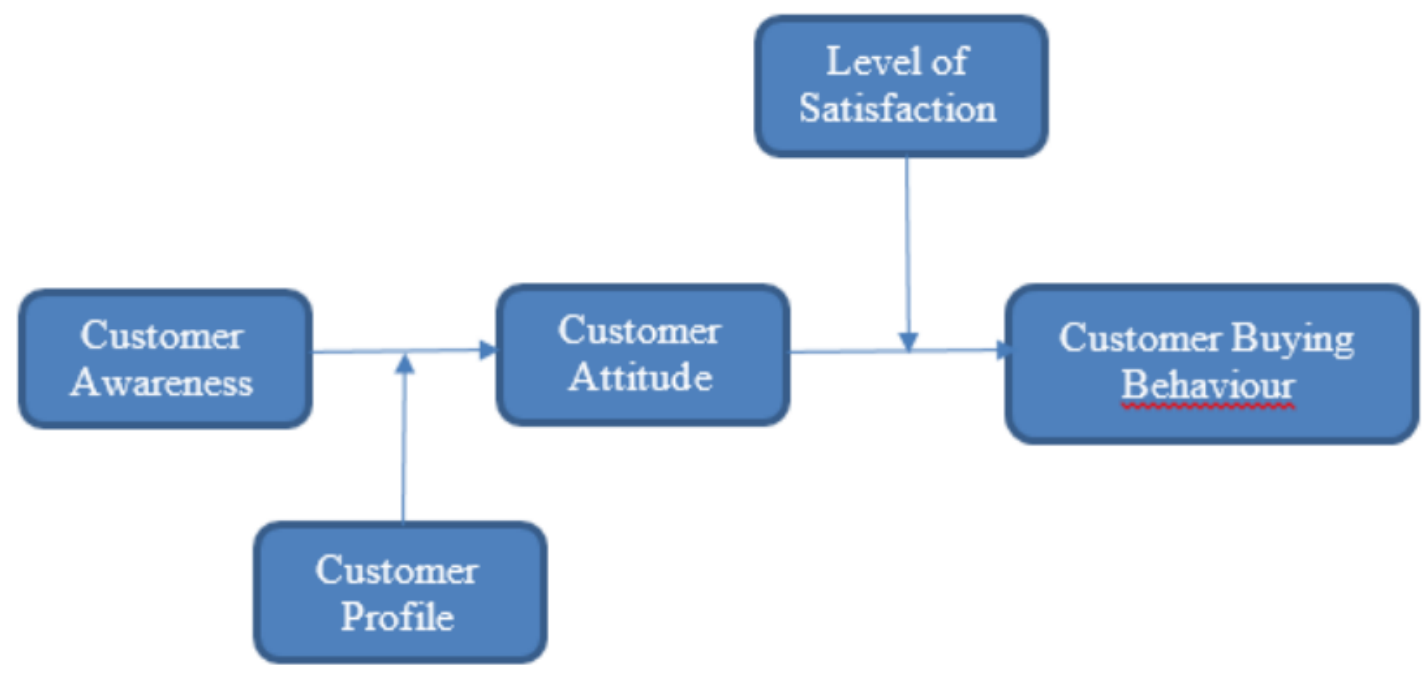




\section{REFERENCES}

[1] Bloch, J., Fallon, D., \& Bitta, R, Study of buying behaviour of branded edible oils. Indian Journal of Marketing, 31 (7), 2006, pp 48.

[2] Cooper, D., \& Schindler, P, Business Research Method (7th ed.). New York: McGraw-Hill., 2008

[3] Dhinesh babu.S , Venkateshwaran.P.S, Marketing problems of edible oil industry in the state of Tamilnadu, Asian Journal of Management, pp 58 - 65, ISSN 22293795

[4] Dr. J.H.Vyas, Imran N. Siddiqu ,Jay K. Dewangan, A study of Edible oil consumption in Raipur city "IRACST - International Journal of Commerce, Business and Management Vol. 2, No.2,2013

[5] Du S., Mroz T.A., Zhai, F., Popkin, B.M, Rapid income growth adversely affects diet quality in China-particularly for the poor! Social Science Medical Journal, 59 (7), 2004, pp 1505-1515.

[6] D. Shanthi and Dr. Ashok Kumar. M. Effectiveness of Television Advertisements on Buying Behaviour of the Women College Students. International Journal of Advanced Research in Management, 7(3), 2016, pp. 21-28.

[7] Economic Survey 2004, by Central Bureau of Statistic. Githitho, M. N, The effects of income expenditure patterns on household food security in low income urban households at Kasarani Division, Nairobi. Kenyatta University, Kenya, 2004

[8] Hallman, W. K., Adelaja, A., Schilling, B., \& Fang, J. T, Consumer Beliefs, Attitudes and Preference Regarding Agricultural Biotechnology. Food Policy Institute Report, Rutgers University, New Brunswick, 2002

[9] Henneberry, S. R., \& Charlet, B, A Profile of Food Consumption Trends in the United States. Journal of Food Products Marketing, vol. 1 (1), 2002, pg. 3-21.

[10] Hussey, J., \& Hussey, R, Business Research: A Practical Guide for Undergraduate and Postgraduate Students. London, Macmillan, 1997

[11] Dr. S. Yuvaraj and S. Bhavani, the Factors Influencing the Buying Behaviour of the Consumers with Digital Payment Modes. Journal of Management, 5(4), 2018, pp. 74-80.

[12] Israel, G. D, Sampling the Evidence of Extension Program Impact. Program Evaluation and Organizational Development, IFAS, University of Florida, 1992

[13] Krai, T.V., \& Rolls, B.J, Energy density and portion size: their independent and combined effects on energy intake. Physiological Behavior, 82(1), 2004, pp 131-138.

[14] Kuria, J. W, Factors that influence clothing preferences and buying practices among the elderly in Korogocho sub-location in Nairobi. Kenyatta University, Moi Library, 1995

[15] Lesser, B., \& Hughes, J, Service marketing, integrating customer focus across the Firm. New Delhi: McGraw Hill, 2006

[16] Lin, W., Somwaru, A., Tuan, F., Huang, J., \& Bai, J, Consumer attitudes toward biotech foods in China. Journal of International Food and Agribusiness Marketing, 18(1\&2), 2006, pp 177-203.

[17] K. Asha and Dr. S. Edmund Christopher, A Study on Buying Behaviour of Customers Towards Branded and Non-Branded Gold Jewellery with Reference to Kanyakumari District, International Journal of Management (IJM), Volume 5, Issue 10, October (2014), pp. 105-114

[18] Malhotra, N. K, Marketing Research: An Applied Orientation. Upper Sadie River, New Jersey: Prentice Hall Pearson International Edition, 2007

[19] Marchant, M. A., Fang, C., and Song, B. (2003). Issues on Adoption, Import Regulations, and Policies for Biotech Commodities in China with a Focus on Soybeans. AgBioForum, 5(4): 2003, pp 167-174. 
[20] K. T. Manivannan and Dr. T. Joseph, A Study on Buying Behaviour of Owners Towards Residential Flats in Urban Areas of Tamil Nadu State, International Journal of Civil Engineering and Technology, 8(11), 2017, pp. 500-507

[21] McDanile, C., \& Gates, R, Marketing Research Essentials. United States: South- Western College Publishing, 2001

[22] Mendez, M.A., Monteiro, C.A., \& Popkin, B.M, Overweight exceeds underweight among women in most developing countries. American Journal of Clinical Nutrition, 81(3), 2005, 714-721.

[23] N. Rajaveni \& Dr. M. Ramasamy "A study on packaging with special reference to edible oil through consumers in Chennai." International Journal of Management (IJM), Volume 3, Issue 2, May-August (2012)

[24] Phytosterols and Health Implications - Efficacy and Nutritional Aspects. Inform, 12, pp 899- 903.

[25] R Prerna, An Empirical Study on Brand Preference Towards Edible oil in Rural Areas with Special Reference to Coimbatore District, Volume : 3 | Issue : 3 | March 2013 | ISSN - 2249$555 \mathrm{X}$

[26] Saunders, L., \& Thornhill, A, Research Methods for Business Students. 2nd edition, London: Prentice-Hall, 2000

[27] Springer, F., \& Kevin, J, Strategic brand concept-image management. Journal of Marketing, 50 (1), 2002, pp 135-14.

[28] Sulzer, S, Do Consumers not care about Biotech Foods or Do They Just Not Read the Labels. Economic Letters, 75 (1), 2005, pp 47-53.

[29] Sulzer, S, Effects of Cheap Talk on Consumer Willingness-to-Pay for Golden Rice. American Journal of Agricultural Economics, 85 (4), 2005, pp 840-856.

[30] Syed Akif Hasan and Muhammad Zeeshan Khan, The Impact of Packaging Characteristics on Consumer Brand Preference, South Asian Journal of Management Sciences Vol. 3, No. 1, (Spring 2009), pp 1 - 10

[31] Wirthgen, B., Kuhnert, H., Altmann, M., Osterloh, J., \& Wirthgen, A. (1999).

[32] Zhong, F., \& Chen, X, Genetically Modified Food, Consumers' Purchasing Behavior and Market Share. China Economic Quarterly, Vol.7, No.3, 2008

[33] Zhong, F., \& Chen, X, How does Biotech Food Labeling Affect Consumers' Purchasing Preference and Market Share in Supermarket? A Case Study of Vegetable Oil in Urban China. Paper for presentation at IAMO Forum 2008, "Agri-Food Business: Global Challenges - Innovative Solutions", June 25 - 27, 2008

[34] Zhong, F., \& Ding, Y, Consumer Awareness and Response to GM Foods in Nanjing. China Rural Survey, 1, 2004, pp 22-27.

[35] Zhong, F., Chen, X., \& Ye, X, GM Food Labeling Policy and Consumer Preference - A Case Study of Actual Edible Oil Sales in Nanjing supermarkets. China Economic Quarterly, Vol.5, No.4, July, 2006, pp 1311-1318.

[36] Zhong, F., Marchant, M.A., Ding, Y., \& Lu, K, GM foods: A Nanjing case study of Chinese consumers' awareness and potential attitudes. AgBioForum, 5(4), 2002, pp 136-144. 